\title{
ALGUNAS IMÁGENES DEL OTRO EN LA LITERATURA ANTIGUA ESLOVENA O QUÉ TIENEN QUE VER LOS ESPAÑOLES CON LOS TURCOS
}

El carácter de toda la sociedad en el territorio esloveno entre los siglos IX y XVI -y sobre todo de los siglos XV y XVI- está fuertemente marcado por los constantes ataques de los turcos y por la organización de la defensa contra ellos. ${ }^{2}$ No es de extrañar, entonces, que la referencia a los turcos ${ }^{1}$ sea un tema constante de la literatura eslovena antigua, en la que la imagen de los turcos la mayoría de las veces está asociada al miedo, a la pobreza, a la ignorancia, a los secuestros y a la muerte. Pero los hechos históricos en distintas épocas provocaban distintas interpretaciones. Para ilustrarlos, en este artículo recurro a tres poemas diferentes para trazar la imagen del Otro -los árabes y los turcos, en concreto- en dos épocas distintas de la literatura antigua eslovena: en la Edad Media y en el Renacimiento.

Siguiendo el orden cronológico inverso empiezo por la obra del fundador de la literatura eslovena, Primož Trubar, en cuyas numerosas páginas se recoge la mayoría de las distintas imágenes de los turcos de su época. La vida personal de Trubar está ya desde su más tierna niñez vinculada al miedo a los turcos (Rupel 1962: 29-30); su obra, sin embargo, ofrece algunos testimonios ajenos a esta experiencia personal.

Según Trubar el peligro de los turcos es una forma del castigo divino (la idea aparece ya en el primer libro esloveno, en el Catecismo del 1550, pero Trubar la desarrolla en Un canto espiritual contra los turcos y todos los enemigos de la iglesia divina - Ena duhovska pejsen zuper Turke inu vse sovražnike te cerkve božje del 1567) ya que, según Trubar, los ataques de los turcos datan del mismo tiempo que el inicio de las misas papales. La penitencia liberará, por lo tanto, a los creyentes de los ataques de los turcos y al mismo tiempo Dios divulgará la única verdadera religión (la protestante) entre los paganos. «Nosotros vivimos, como su merced ducal sabe, en la frontera y por lo tanto en el matadero y nos tratan como a las ovejas destinadas a matar que ahogan todos los días,» escribe en el Postillum cirilico del 1563, y añade (Esta primera parte del Nuevo Testamento - Ta prvi dejl tiga noviga testamenta, 1557):

Los dos pueblos de los territorios de Eslovenia y Croacia me dan mucha pena y deberían darla a cualquiera no sólo por el hecho de tener que vivir y habitar en la frontera turca y no poder ir ni fugarse a ninguna parte y porque el turco ha conquistado y sigue conquistando la mejor y la mayor parte del campo y de las ciudades matando, ahogando, raptando

\footnotetext{
${ }^{1}$ En este sentido, los finales del siglo XV fueron los más duros: entre 1469 y 1483 hubo aproximadamente treinta ataques, entre los cuales algunos abordaron todo el territorio esloveno y duraron hasta un mes. Entre 1491 y 1499 hubo once, entre 1522 y 1532 el número de ataques alcanza veintiuno, hasta 1570 hubo ya tan sólo ataques esporádicos que duraron poco tiempo y en los que participaron menos soldados, que asimismo se localizaron en el sur del territorio Esloveno.

${ }^{2}$ La defensa, al principio, se limitaba a la autodefensa (preparación de las señales en fuego, fortificación de las ciudades, castillos, iglesias y participación en los combates), y luego resultó en la organización de una serie de fortificaciones fronterizas en la marca en Eslavonia y en algunas partes de Croacia junto al río Kolpa.
} 
a las mujeres y los niños para luego separarlos y venderlos a la esclavitud, sino bien porque saben muy poco o nada (porque no les enseñan bien) sobre los más necesarios y útiles postulados de la verdadera fe cristiana, cuyo conocimiento precisa cada hombre ilustrado para lograr el bienestar de su alma y la consolación suprema. (Texto traducido a partir de la edición en Slovenski protestantski pisci, p. 72).

Pero a pesar de ello la imagen de los turcos en Trubar no es exclusivamente negativa:

Al contrario hay también turcos y turcas decentes, respetables y modestos. [...] Muchos nobles turcos, también los del origen más noble, bautizan a sus hijos en secreto y cuando éstos se hacen mayores, les mandan al extranjero a los cristianos para que aprendan de ellos la religión cristiana. (Posvetilo en La primera parte en letra glagoliana del Nuevo testamento - Glagolski prvi del novoga testamenta, 1562, en: Slovenski protestantski pisci, p. 123).

Como los pueblos paganos tienden a convertirse al cristianismo, esto incita a Trubar a poner todas sus fuerzas en una futura misión de la iglesia protestante en el Oriente, para la que sirve la preparación de los textos publicados en el alfabeto cirílico y glagolítico, y en 1567 hasta se desplaza clandestinamente a Ljubljana para entrevistarse con los turcos presos en el castillo de Ljubljana. Sus informaciones sobre el Corán y sobre la fe musulmana les sirven a los teólogos alemanes (sobre todo a Jacobo Andrea quien le pidió que se entrevistara con los turcos) para la preparación de los sermones contra ellos, iniciando, a la vez, un estudio más profundo de la religión musulmana y de sus costumbres en todo Europa.

Para Trubar la religión es el criterio de superioridad moral. Así lo demuestra también De esta iglesia divina contra sus enemigos llanto y oración - Te cerkve božje super nje sovražnike tožba inu molitev incluida en Tres canciones espirituales - Tri duhovske pejsni:

O Bug, zakaj ti dopustǐs tujo Cerkov zatreti? Ti vejš inu dobru vidiš, de nas hote razdreti.

Turki, hudi neverniki, malikovski služabniki nas hte s korenom zdreti.

Zatu kir se vkup snidemo, od tebe pridigujemo inu se prov obhajemo, otroke prov krščujmo, na tujga sinu kličemo, za tujo milost prosimo, tebe so vsem čestimo.

Le-tu oni vse kolneju, nas zatu zlo sovražo, za kecarje vun dajejo. Nesramno čez nas lažo, de smo božji suprniki, vseh svetnikov sovražniki, dolžni na vsi nesreči.
Ves čaz nas tudi pravijo, da više zašpotujmo: nih zapuvid, kar stavijo, mi cilu zamečujmo, novo, falš vero vučimo, božje službe razdiramo, zato so draga lejta.

Obtu nas tirani hudi love, more, pregano; koker te škodlive ludi nas po svejtu rezgano. Vse verne ter pridigarje drže za hude puntarje, začetek vsiga zlega.

Čez tako silo, krivico, komu hočmo tožiti? Samuč tebi, kir z desnico moreš nom podstopiti, kir te ludi izraelske si iz ječe faroniske z močno roko odrešil.
Natu mi tudi tožimo z grliskim klagovanem inu te milo prosimo, de s tujem pomaganem prideš nom h troštu, hpomočjan, zakaj vsak verni je obran vso žaht revo, nadlugo.

Zatu te hočmo nuč ter dan vselej povsod hvaliti, pelati pošten ta naš stan, tujo čast rezglasiti, de boš s tujem sinum spoznan, od vseh ludi prov poštovan, $\mathrm{h}$ timu daj tuh duh, amen. 
También en la primera estrofa de este poema aparecen los turcos. Y si al principio su imagen concuerda con la imagen negativa que éstos solían provocar, las siguientes estrofas nos despistan, ya que a partir de la tercera estrofa Trubar enumera todas las dificultades que los protestantes eslovenos tenían con sus adversarios, los miembros de la contrarreforma eslovena, los que rechazaban sus uniones y prácticas religiosas, maldeciéndoles, odiándoles, llamándoles unos traidores, que mentían sobre ellos, culpándoles de todas las calamidades. También les acusaban de no respetar los mandamientos, de enseñar su fe errónea, de destrozar el oficio divino, y, además, les perseguían y mataban, proclamándoles rebeldes, culpables de todo el mal. Las últimas tres estrofas que conluyen el poema son una petición al Dios omnipotente para que les ayude a seguir en su 'antigua religión verdadera' y a hacerla expandir por todo el mundo.

Aquí, de este modo, la imagen del turco parte de la imagen negativa de ellos para convertirse en el sinónimo de los miembros de la contrarreforma. Así la diversidad de la imagen de los turcos en Trubar se completa: los turcos pueden ser bien un sinónimo de lo más hostil, y de lo más salvaje, bien buenos, cegados por la religión errónea, paganos, en fin, que después de la caída del Imperio otomano podrían convertirse en verdaderos cristianos. Te cerkve božje super nje sovražnike tožba inu molitev añade otra visión que funde la imagen pagana con la de los enemigos religiosos, vinculándola a las atrocidades más grandes de los turcos: los miembros de la contrarreforma se convierten en los turcos -aquí la palabra funciona casi como un insulto- porque su religión es diferente y sus métodos de persecución de los reformistas son muy violentos.

Una mezcla curiosa de la imagen del pagano con el uso de los gentilicios turco y español puede hallarse en el poema tradicional esloveno que se intitula El peregrino de Santiago de Compostela - Romar sv. Jakoba Komposteljskega:

Kdor mi hoče romar biti, romar svetga Jakoba, more zjutraj zgodaj vstajat, zvečer pozno spat iti, kako je vstajal kraljič, le-ta lepi španski kralj, ko kraljica je menila, de je hodil $\mathrm{k}$ moškram $\mathrm{v}$ vas.

Eno jutro je zared vstala šla pogledat za njim.

Ker ga je bla ona najdla v leti svetli kamrici, ker je on zvesto preklečal per podob Šent-Jakoba. Tukaj je Boga on prosil, de b' mu dal en srečni pot, k' se na božjo pot zdviguje.

On ima zraven sebe le-to palco romarsko ino debeli roženkranc. Zraven tudi je ležalo za njegov popotni ronc tri mošnje, vse polne dnarjev, ker on gre na božjo pot.
Perve dnarje je napravil, de jih bom ubogejme dajal vsim sroticam in beračam, kter po hišah prosijo. Druge dnarje je napravil ubogejme jih bo dajal vsim cerkvam, ki so ubožne. Tretje dnarje sam bo vžil, ker pojde po božjih potih.

Tak je regla mu kraljica: »Kaj prevzgodaj vstajate? Al bom sama zdaj srotica, kam, gospod, vi pojdete? Na pot se vi napravljate, nam pa nič ne poveste.«

Tak je rekel mladi kralj: »Grem v' lepo Galicijo, notri h' svetim Jakopu.« Tako regla pa kraljica: »Daleč ni za vas hodit': če vas Turki vgledajo, vas v ječo veržejo.«
Še ' $\mathrm{z}$ doma on vzdvigne, kamur daleč je prišal, notri v' globoko Turčijo. Gor in dol po Turškim hodi, moli sveti roženkranc; gor in doli premišljuje, kje bi prišal h' svetim grob'. Dobili so ga carjov' hlapci, Vrgli v' ječo ga tamno.

To je zvedila kraljica, se naprav po romarsko, se deržala ko srotica, z' sabo vzela citrice, aj te citre pisane. Šla v' Turčijo je globoko. Gor in dol po Turškim gre, in je citrala lepo.

Turški car jo je zagledal, tak ji pravi, govori: »Kaj češ, ubožec, lona jmeti. $\mathrm{K}$ nam tako znaš citrato?« »Lona jez nič drugega nočem, kot jetnika vašiga.« Car dovol', kar ona hoče, Dal ji ' $\mathrm{z}$ ječe romarja. 
Según Grafenauer (1937/38 a :339-341) el motivo principal del romance tradicional esloveno sobre el peregrino al Santiago de Compostela tiene su origen en la lírica tradicional europea medieval, inspirándose a la vez en el motivo de la mujer noble que vestida de peregrino libera del cautiverio a su marido, cantando. ${ }^{3}$

Pero la primera parte introductoria del romance resulta muy interesante desde el punto de vista de la historia de mentalidades, facilitando, a la vez, la ubiación cronológica del romance. En ella se narra en qué consiste la preparación para la peregrinación del «rey, este guapo rey español» («kraljič - le-ta lepi španski kralj»), por lo cual la reina (quien desconoce su intención) piensa que el motivo de esta conducta del rey es el adulterio. Esta parte del romance revela que los hábitos medievales descritos en él son muy antiguos, porque es evidente que los que cantaban y recitaban este romance en el momento de hacerlo (se supone que muy posterior a su nacimiento), ya no lo entendían. Precisamente este desconocimiento origina la deducción errónea: la abstinencia sexual del rey está interpretada por el cantante (y por la reina) como una prueba de su infidelidad. ${ }^{4}$

También el contenido de la segunda parte del romance revela las confusiones que de nuevo testimonian que el tema principal del romance es muy antiguo. No cabe duda que el santuario al que originalmente se dirige el rey es el santuario del apóstol Santiago en Compostela, y los turcos, de los que le habla la reina, son originalmente los moros españoles, para los que -como veremos más tarde- la lírica tradicional eslovena suele emplear la palabra «zamorc ${ }^{5} »$ (la palabra proviene del nombre propio Morec, del español e italiano «moro»). Pero la confusión entre Santiago de Compostela y Jerusalén, y la sustitución de los moros por los turcos, no es sino otro testimonio sobre cómo la noción del camino de Santiago y de las circunstancias históricas de la España medieval se iban perdiendo entre el pueblo esloveno, y cómo la realidad histórica en seguida se encargaba de ofrecer otros ejemplos, más reales y por lo tanto más cercanos a las mentes de la gente que cantaba y/o recitaba el romance sobre el peregrinaje a Compostela. Por escritos de Primož Trubar, ${ }^{6}$ sabemos que en el siglo XVI los eslovenos ya sabían poco sobre el santuario del apóstol en Compostela, aunque no deja de ser curioso que a pesar de todo la noción del santuario permanece tanto en la lírica tradicional, ${ }^{7}$ como en el poeta clásico esloveno, France Prešeren, ${ }^{8}$ en el pleno Romanticismo.

La comparación con la versión alemana del romance y con un fragmento en prosa en la lengua holandesa, hecha por Ivan Grafenauer (1937/1938 $: 344),{ }^{9}$ revela que la fuente

3 Al que corresponde, a su vez, el motivo del hombre noble que vestido de peregrino libera a su mujer del cautiverio pagano, mahomedano, sarraceno o moro.

«Il moro saracino» aparece en algunos poemas sobre el héroe nacional esloveno, Kralj Matjaž (el rey Matías Korvino), en las variantes sobre Kralj Matjaž in Alenčica.

4 La reina piensa que el rey la engaña con una «mojškra» (del italiano maestras), es decir, con las guardadamas que a partir del siglo XI por la influencia del ideal del comportamiento francés ayudaban en la instrucción de las hijas nobles, siendo víctimas, a su vez, de una mala reputación.

5 Hoy la designación coloquial para el «negro».

${ }^{6}$ En la dedicatoria alemana a Maximiliano II. que data de 12. de enero de 1562, Trubar, al atacar los peregrinajes más populares entre los eslovenos ya no menciona la peregrinación hacia Santiago de Compostela, sino que habla de los peregrinajes a Roma, Loreto, Otinga y Aquisgrán.

7 Uno de los poemas posteriores (SNP, no. 6682, III, p. 794) dice que el peregrino a Santiago de Compostela tiene que vestir igual que el apóstol Santiago, cuando iba a Galicia vestido de peregrino.

8 Prešeren empieza uno de sus sonetos con Marskteri romar gre $v$ Rim, $v$ Kompostelje ( $«$ Más de un peregrino va a Roma, a [Santiago de] Compostela»). 
directa más probable del poema fue un desconocido romance español ${ }^{10}$ que dataría del período entre los siglos VIII y XII, ya que los peregrinos en el camino de Santiago sentían el peligro y los frecuentes ataques de los moros hasta los inicios del siglo XIII. Es bastante probable, por lo tanto, que el romance se trasladase al esloveno por medio de un peregrino, bien clérigo, bien escolar, hasta los finales del siglo XIII.

Cabe destacar otra mención de la corte española en la lírica tradicional eslovena: el motivo aparece en la balada sobre Lepa Vida (De la hermosa Vida), uno de los motivos más constantes de toda la literatura eslovena. Ya la lírica tradicional ofrece variantes del motivo, y como es lógico, el motivo con el paso del tiempo y según la visión personalizada de cada autor aún se va ramificando aún más. ${ }^{11}$

Ivan Grafenauer logra acumular 19 variantes de esta balada tradicional (Grafenauer 1943). En todas ellas aparece un negro/un moro (el mismo «zamorc» del Romance del Peregrino a Compostela) que con el desengaño convence a la bella y joven madre Vida para que entre en su barco y luego la rapta, llevándosela a España.

9 El romance alemán «Graf von Rom» se ha conservado en dos ejemplares de pliegos sueltos. La versión del romance es anterior a la versión adaptada de un «buch» (libro). Su contenido en general se corresponde al contenido del romance esloveno, pero también hay unas diferencias importantes: los protagonistas son unos condes de Roma; la versión eslovena tiene 16 versos, la alemana 192; el rey pagano quiere que la mujer del conde cautivo venga sola a rescatarlo, a lo cual ella se niega; a pesar de todo, la mujer viste de monje y con un laúd en la corte del rey pagano rescata, cantando, a su marido que no la reconoce. Una vez rescatado el marido, la mujer vuelve a casa, y el marido sigue su peregrinaje. Cuando al volver de su peregrinaje vuelve a casa, reclama a su mujer no haberle ayudado; también los amigos del marido quieren acusarla de adulterio, pero entonces la mujer viste de monje y así deja conocerse. Aunque el romance en alemán no menciona ningún lugar concreto, en se habla de Jerusalén y no de Santiago de Compostela.

${ }^{10}$ Esta hipótesis se ve reforzada también por el trato entre los cónyugues (se hablan mutuamente de Usted), y por algunos procedimientos formales atípicos del romance en esloveno: en el verso trocáico hay unos ejemplos de rima asonante (que es muy rara en la poesía eslovena).

${ }^{11}$ La versión de Lepa Vida de Andrej Smole sirve, probablemente, de fuente a France Prešeren. A base del personaje de Lepa Vida Josip Jurčič escribe una novela sobre una mujer infiel que es a la vez una mujer inmadura y demasiado mimada que después de cometer un adulterio vuelve a su marido con lo cual hunde a los dos. Risto Savin utiliza este motivo para su opera. Josip Vošnjak utiliza el personaje para escribir la tragedia sobre un burócrata corrupto que vende a su hija a un negociante italiano. Ivan Cankar convierte el personaje de Lepa Vida en un símbolo del anhelo constante: al principio se anhela el extranjero, y desde el extranjero, la propia patria. Para Avgust Žigon Lepa Vida es el símbolo de la naturaleza inconstante de la mujer. Jakob Kelemina va aún más allá en sostener que Lepa Vida es un ser poseído por el demonio.

En 1987 Jože Pogačnik logra acumular 43 elaboraciones literarias del motivo de Lepa Vida a partir del año 1832: France Prešeren, Od Lepe Vide (1832), Jusip Jurčič, Lepa Vida (1877), Jože Vošnjak, Lepa Vida (1893), Oton Župančič, Skrinja (1894), Cvetko Glar, Lepa Vida (1900), Ivan Cankar, Lepa Vida (1904), Ivan Cankar, Lepa Vida (1911), Juš Kozak, Lepa Vida (1913), Dragan Šanda, Lepa Vida (1915), Igo Gruden, Pesem o lepi Vidi (1920), Cvetko Golar, Lepa Vida (1921), Bogomir Magajna, Vida (1921), Bogomir Magajna, Privid lepe Vide (1925), Alojz Gradnik, Devin (1926), Oton Berkopec, Lepa Vida (1928), France Bevk, Žerjavi (1932), Miran Jarc, Slovenski soneti (el segundo soneto) (1938), Vinko Beličič, Molitev za domovino (1939), Prežihov Voranc, Ljubezen na odoru (1940), Janko Moder, Lepa Vida (1944), Ferdo Kozak, Vida Grantova (1946), Boris Pahor, Vrnitev Lepe Vide (1948), Stanko Vuk, Lepa Vida (1949), Boris Pahor, Mesto v zalivu (1955), Asta Anidar, Lepa Vida (1956), Jože Tomažič, Lepa Vida (1956), Miloš Mikeln, Petra Šeme pozna poroka (1956), Vinko Trinkaus, Lepa Vida (1960), Edvard Kocbek, Neznanka (1963), Edvard Kocbek, Zamorska (1963), Mart Ogen, Cool št. 2 (1964), Emil Miklavčič, Vidina pesem (1966), Filip Fischer, Lepa Vida (1967), Miško Kranjec, Lepa Vida prekmurska (1972), Antón Ingolič, Onduo, moj črni fant (1972), France Pibernik, Lepa Vida (1973), Bruna Pertot, Grljanska pomlad (1977), Matjaž Kmecl, Lepa Vida ali problem svetega Ožbalta (1977), Beno Zupančič, Lepa Vida (1978), Rudi Šeligo, Lepa Vida (1978), Srečko Rijavec, Lepa Vida (1981), Marjeta Novak, Kristina (1985), Alenka Goljevšček, Otrok, družina, družba ali lepa Vida (1987). 


\section{DE LA HERMOSA VIDA}

Estaba ante el mar Vida la hermosa a su vera lavando la ropa.

Por el gris mar un moro navega, detiene su barca y la interpela: «ipor qué tu rostro no es tan rosado, ¿por qué no florece como antaño como en aquellos hermosos años?»

Responde así la hermosa Vida: «¿Cómo ser rosada y floreciente si la desgracia no lo consiente?; mi niño está pálido y enfermo y a mí me guiaron malos consejos; me he casado con un hombre anciano. La alegría es un deseo vano; todo el día, triste, llora el niño, y tose de noche mi marido.»

Responde el moro a Vida la hermosa: «si un gran dolor en tu casa mora, ven conmigo a través del gran mar tus aciagas penas a sanar. Y más te digo mi tierna Vida, me ha enviado la reina de España a que amamantes al principito. Al futuro emperador, su hijito. Lo nutrirás y lo acunarás, su blanca camita le harás, lo adormirá tu dulce cantiga, y olvídate de otra fatiga.»

Subió a la barca la hermosa Vida; y cuando dejaron la orilla y la barca surcaba a la aguas, Vida estalla en llanto y habla: «iOh, qué he hecho yo desgraciada! ¡Oh, a quién he dejado en mi casa a mi pobre criatura doliente y a mi esposo anciano e indigente!»

Después de pasadas tres semanas, Vida conoce a la soberana. Se alza Vida en hora temprana para ver el sol en la ventana. Para atenuar su enorme dolor comienza a hablar al rosado sol: «Oh sol, decidme, fúlgidos rayos, ¿qué hace mi niño, mi hijo malsano?»
«¿Qué podría tu niño hacer? Ayer ardieron velar por él, y tu esposo ha dejado la casa, en tu búsqueda por el mar vaga, te busca y llorando se lamenta, el pecho le estallará de pena.»

Cuando sale de noche la luna, Vida se asoma a la ventana, para mitigar su pena aciaga, se dirige a la pálida luna: «Luna, decidme, frágiles rayos, ¿qué hace mi niño, mi hijo malsano?»

«¿Qué puede hacer ahora tu niño? Hoy tu niño ha sido sepultado y tu esposo ha dejado la casa, en tu búsqueda por el mar vaga, te busca y llorando se lamenta, el pecho le estallará de pena.»

Incesante es el llanto de Vida, se acerca y le pregunta la reina: «¿Qué desgracia te sucede Vida que lloras tan angustiada y tierna?» Triste responde Vida a la reina: «Cómo no llorar, desgracia mía, mientras lavaba una copa de oro de la ventana se me ha caído, desde aquí, este alto lugar la copa de oro ha caído al mar.» La calma y dice la soberana: «No llores y humedece tu cara. Otra copa de oro compraré y responderé por ti ante el rey; con mi hijo ve ahora a jugar, así puedes calmar tu pensar.»

La reina compra una nueva copa, responde al rey por Vida la hermosa, que cada día se asoma en vilo para llorar, triste, a sus queridos. ${ }^{12}$

\footnotetext{
${ }^{12}$ Resproduzco aquí la traducción De la hermosa Vida en la versión de France Prešeren y en la traducción de Juan Octavio Prenz (Prešeren 2003: 31-35).
} 
Hay tres variantes del destino de la joven madre Vida:

1) Las variantes con el final trágico: Lepa Vida no quiere ser esclava del moro y por ello salta del barco, ahogándose en el mar. Se supone que esta variante de la balada data del período entre los siglos IX-XI, porque en ella la bella y fiel madre joven está raptada como una esclava, lo cual coincide con los acontecimientos históricos, en los que los moros, después de tomar Sicilia (en 827), entraban al Mediterráneo occidental (en 866 asediaban la República de Ragusa y, saqueando por toda la costa del Adriático, en 875 llegan incluso hasta la ciudad de Grado/Gradež), raptando los esclavos que luego vendían en diferentes puertos de África y España. Además de describir un peligro real que en aquel entonces representaban los Moros, en esta variante de la balada aparece otro motivo: el del salto al agua, que es mucho más antiguo, ya que proviene de la época precristiana, de las relaciones históricas sobre las mártires antióquicas que en la época del Diocleciano prefirieron la muerte a la profanación de su fe (Grafenauer 1943: 198). También la hermosa Vida elige la muerte para poder morir como (y, de este modo, seguir siendo) ${ }^{13}$ madre y mujer.

2) Las variantes con el final elégico, como la que está reproducida aquí: la dimensión trágica y activa del primer tipo está sustituida por la actitud pasiva, llena del rencor. El número los personajes que en el primer grupo de variantes del poema eran tres ${ }^{14}$ aumenta, ya que el moro se convierte en un mediador para la reina de España y para su hijo. También aquí el hijo de la hermosa Vida está presente mediante el habla de los demás, pero además de éste, aparece también su viejo marido enfermo. La protagonista sufre una modificación importante: en vez de tomar una actitud activa, en el momento de darse cuenta de que está raptada por el moro, rompe a llorar. ${ }^{15} \mathrm{Su}$ actitud pasiva y el llanto continúan también en la corte. Y cuando la reina la pregunta por la razón de su tristeza, Vida miente, diciendo que se le había caído una copa de oro al mar. En la corte la hermosa Vida tiene que ocultar su verdadera identidad, pero también la verdadera causa de su tristeza (Pogačnik 1988: 27). Estas pueden ser reveladas tan sólo ante la luna y el sol ${ }^{16}$ a los que Vida pregunta por su familia. Ellos le responden que su hijo murió y que su marido viejo la busca por todo el mundo. En esta variante -la más expandida- es, por lo tanto, imposible superar este anhelo y lograr la realización del deseo de Lepa Vida.

3) El tercer grupo de las variantes son las con el final feliz que cuentan la vuelta de la hermosa Vida a su hogar. Esto significa que Lepa Vida ni acepta al moro, ni la nueva

${ }^{13}$ El moro que con el desengaño (una medicina para su hijo enfermo) rapta a Vida para hacerla su mujer y nodriza de su hijo; la Vida misma que en el momento decisivo cree en su mentira por lo cual también se castiga a sí misma; el hijo de Vida que no aparece en el poema pero que sirve de motivo a todo el acontecimiento.

${ }^{14}$ El breve momento de llanto es suficiente para el traslado -mítico, no real- a España.

${ }^{15}$ La luna y el sol de este modo se convierten en otros elementos mitológicos, en los verdaderos conocedores del destino humano y los mediadores, capaces de unir los acontecimientos conocidos/desconocidos y los lugares lejanos (Terseglav 1987: 58).

${ }^{16}$ El tema de esta balada tradicional se ve reflejada en la epopeya romántica por Matija Kračmanov Valjavec del 1867: la eslovena Sonca está raptada de un castillo en Carniola por un Turco. Luego es vendida como esclava y en Turquía quieren convertirla a la religión musulmana, ponerle el nombre de Zaira y casarla con el sultán. Su hermana Zora se casa con el viajero español don Almiro, que vino a ayudar a la guerra. Después de la boda los novios viajan a España. Allí Zora da a luz su hijo y le pide a su marido que libere de la prisión turca a su hermana. Don Almiro logra liberar a la hermana Zaira, que su hermana desconoce y de la que está celosa. A la vuelta del peregrinaje a Santiago de Compostela pasa por su casa un esloveno del que de joven Sonca había estado enamorada y la reconoce. Luego Sonca se casa con su amor y juntos vuelven a Carniola. 
vida en la corte de España, ni la añoranza, ni el anhelo por el pasado. Rechaza totalmente la nueva realidad y vuelve con la ayuda del sol a su casa. Su vuelta fantástica puede explicarse por la influencia de las leyendas medievales que eran populares sobre todo en el siglo XIII (Grafenauer 1943: 328). Pero aun así no deja de ser curiosa la razón por la que Lepa Vida vuelve a su familia: a su hijo (quien en esta variante no muere) y a su matrimonio infeliz. Parece que además de la vuelta a su hijo, una de las razones es también el placer en la desgracia, por muy contradictorio que éste parezca. Pero también esta contradicción es otro rasgo antiguo del poema, puesto que en todo el occidente el placer del amor desde siempre (y sobre todo desde la época medieval) estaba relacionado con un cierto grado del sufrimiento.

En la balada sobre Lepa Vida nos encontramos de nuevo con los moros y la corte española (la reina española). También aquí la imagen de España está vinculada a la imagen de la España musulmana (probablemente de los tiempos del Califato de Córdoba), por lo cual también la reina de la que habla el poema era bien una mujer del emir, bien una mujer del califa. Esto significa que la aparición del poema cronológicamente puede situarse entre los siglos IX y XI. La conclusión sobre la antigüedad del poema se ve por una parte apoyada por el esquema métrico de aliteración del original esloveno y por otra parte por las numerosas variantes del poema: las modificaciones del tema principal que estas variantes ofrecen significan que los que cantaban y/o recitaban el poema desconocían tanto el contexto histórico en el que se había desarrollado el poema, como la noción de la esclavitud a la que estaba sometida la hermosa Vida.

Además de los reyes españoles ya mencionados en el romance tradicional sobre el peregrino a Santiago y en la balada eslovena de Lepa Vida, la lírica tradicional ofrece otras menciones de los (reyes) españoles, a saber: la balada Zarika y Sončica - Zarika in Sončica, ${ }^{17}$ Brajdika y Ančika - Brajdika in Ančika, La santa Bárbara, echada en prisión - Sv. Barbara, v ječo vržena, La santa Ursula disparada - Sveta Uršula streljana, La joven Breda - Mlada Breda, La Novia desgraciada - Nesrečna nevesta, La reina polaca - Poljska kraljica. En todos ellos los reyes españoles son sinónimos de paganos; «Zamorci», es decir, los moros, en general suelen desempeñar un papel negativo en la lírica eslovena tradicional, dando fe, a la vez, de la antigüedad de estos poemas.

La lectura paralela de los tres poemas elegidos revela que el criterio principal en la concepción del Otro en todos ellos es el criterio de la religión. En el caso de Trubar los turcos son percibidos como el Otro, pero en el poema De esta iglesia divina contra sus enemigos llanto y oración - Te cerkve božje super nje sovražnike tožba inu molitev por diferencias religiosas que estriban entre los dos contrarios de la época, la denominación de los turcos se utiliza en la forma de insulto, designando los partidarios de la Contrarreforma eslovena. El romance tradicional El peregrino de san Santiago de Compostela Romar sv. Jakoba Komposteljskega ofrece una fusión de gentilicios tan distintos como los son los turcos y los españoles, en la cual los dos se identifican con los paganos por pertenecer a una religión distinta. El rey español en el sentido del rey pagano y musulmán aparece también en otros poemas tradicionales y también en el poema tradicional De la hermosa Vida, cuyo motivo de anhelo constante es uno de los motivos más extendidos de toda la literatura eslovena. La mención del rey español en la lírica eslovena tradicional es un testimonio de la antigüedad de cierto poema, pero al mismo tiempo una señal de la incomprensión del Otro: ¿cómo si no deben explicarse las confusiones entre los turcos y los españoles que (también en el sentido del dicho esloveno 'ser pueblo español') se utilizan como sinónimo de algo lejano y totalmente desconocido para el hablante? 


\section{BIBLIOGRAFIA SELECTA:}

Grafenauer, Ivan (1937/1938): «Slovenska narodna balada o Lepi Vidi». Dom in svet, 50, 230-237.

Grafenauer, Ivan (1937/1938a): «Slovenska narodna romanca o Romarju Sv. Jakoba Kompostelskega». Dom in svet, 50, 338-348.

Grafenauer, Ivan (1939). «O Zariki in Sončici in še kaj o 'španskih' junakih». Dom in svet, 51, 78-89.

Grafenauer, Ivan (1939a): «Poljska kraljica». Dom in svet, 51, 224-228.

Grafenauer, Ivan (1939b): «Še Mavri v narodni pesmi». Dom in svet, 51, 281-285.

Grafenauer, Ivan (1943): Lepa Vida. Študija o izvoru, razvoju in razkroju narodne balade o Lepi Vidi. Ljubljana: Akademija znanosti in umetnosti.

Pogačnik, Jože (1988): Slovenska Lepa Vida ali hoja za rožo čudotvorno (Motiv Lepe Vide v slovenski književnosti). Ljubljana: Cankarjeva založba.

Prešeren, France (2003): Cantos. Kranj; Celovec; Ljubljana; Dunaj: Mestna Občina; Mohorjeva.

Rupel, Mirko (1962): Primož Trubar, življenje in delo. Ljubljana: Mladinska knjiga.

Rupel, Mirko (ur.) (1966): Slovenski protestantski pisci. Ljubljana: Slovenska matica.

Šmitek, Zmago (1985): Klic daljnih svetov: Slovenci in neevropske kulture. Ljubljana: Borec.

Štrekelj, Karel (ed.) (1895-98): Slovenske narodne pesmi iz tiskanih in pisanih virov. 4 zvezki. Ljubljana: Slovenska matica.

Šundalič, Zlata. (1989): «Mit o Lijepoj Vidi». En: Srednji vek v slovenskem jeziku, književnosti in kulturi. Ljubljana: Filozofska fakulteta (Obdobja, 10).

Terseglav, Marko (1987): Ljudsko pesništvo. Ljubljana: DZS.

\section{NEKAJ PODOB DRUGEGA V STAREJŠI SLOVENSKI KNJIŽEVNOSTI ALI KAJ IMAJO SKUPNEGA ŠPANCI IN TURKI}

Prispevek analizira podobo Drugega, ki temelji na drugačni veri: ustavi se ob podobi Turkov pri Trubarju (Te cerkve božje sovražna tožba inu molitev) ter podobi Turkov in Špancev v slovenski ljudski pesmi (Romar sv. Jakoba Komposteljskega, Lepa Vida). Trubarjeva podoba Turkov po eni strani ustreza splošni negativni sodbi o njih, a je iz navedenega besedila obenem tudi jasno, da ne gre za resnične Turke, pogane, temveč Trubarjeve religiozne antagoniste, protireformatorje. Zanimivo zlivanje podobe poganov (mavrskih) Špancev in Turkov najdemo v pesmi Romar sv. Jakoba Komposteljskega, iz katere je razvidno, da pevec/pripovedovalec ni več razumel španskega zgodovinskega konteksta (pesem je najverjetneje nastala v 12. stoletju in jo je k nam zanesel kak romar), zato jo je prilagodil sodobnejši in razumljivejši izkušnji s Turki. Španski dvor je omenjen tudi v Lepi Vidi. Tudi tokrat je razvidno, da gre za pojmovanje poganskega, mavrskega okolja. Sicer pa omemba španskega kralja v slovenski ljudski pesmi praviloma priča o izredni starosti tega gradiva. 